\title{
Pedagogias da masculinidade: reflexões acerca de processos de subjetivação de homens professores da EJA
}

\author{
Avelino Aldo de Lima Neto \\ Instituto Federal de Educação, Ciência e Tecnologia do Rio Grande do Norte, Natal, RN,
}

Brasil

\begin{abstract}
Rita de Cássia Angelo da Silvaiiie
Instituto Federal de Educação, Ciência e Tecnologia do Rio Grande do Norte,

Canguaretama, RN, Brasil

Robério Nunes Maiaiiii

Universidade Federal do Rio Grande do Norte, Natal, RN, Brasil
\end{abstract}

\begin{abstract}
Resumo
O objetivo deste artigo é compreender, por meio dos discursos de três homens professores da Educação de Jovens e Adultos, os modos como a masculinidade hegemônica atuou em seus processos de subjetivação. Pretende-se revelar a negação da sensibilidade como dimensão essencial da pedagogia da masculinidade, apontar as ambiguidades das experiências corporais no processo de tornar-se homem e, por fim, desvelar os enfrentamentos vividos pelos participantes, relativamente à masculinidade no processo de construção da identidade docente. A pesquisa é qualitativa, com enfoque exploratório. Adotam-se entrevistas semiestruturadas para a construção dos dados. Os resultados apontam para uma tensão constante entre o inatingível ideal da masculinidade hegemônica e a ruptura criativa com esse parâmetro.
\end{abstract}

Palavras-chave

Masculinidade. Docência. Subjetividade. Educação de Jovens e Adultos.

\section{Pedagogies of masculinity: reflections on processes of subjectivity of male EJA teachers}

\begin{abstract}
The objective of this article is to understand, through the speeches of three male teachers of Youth and Adult Education, the ways in which hegemonic masculinity acted in their processes of subjectivation. The aim is to reveal the negation of sensitivity as an essential dimension of the pedagogy of masculinity, to point out the ambiguities of bodily experiences in the process of becoming a man and, finally, to unveil the confrontations lived by the participants, regarding masculinity in the process of constructing the teaching identity. The research is qualitative, with an exploratory focus. Semi-structured interviews are adopted for the construction of the data. The results point to a constant tension between the unattainable ideal of hegemonic masculinity and the creative rupture with this parameter.
\end{abstract}

\section{Keywords}

Masculinity. Teaching. Subjectivity. Youth and Adult Education.

Educ. Form., Fortaleza, v. 6, n. 2, e4378, maio/ago. 2021

DOI: https://doi.org/10.25053/redufor.v6i2.4378

https://revistas.uece.br/index.php/redufor/index 


\title{
Pedagogías de la masculinidad: reflexiones sobre procesos
}

de subjetividad de profesores varones de EJA

\begin{abstract}
Resumen
El objetivo de este artículo es comprender, a través de los discursos de tres hombres profesores de Educación de Personas Jóvenes y Adultas, las formas en que la masculinidad hegemónica actuó en sus procesos de subjetivación. El objetivo es revelar la negación de la sensibilidad como dimensión esencial de la pedagogía de la masculinidad, señalar las ambigüedades de las experiencias corporales en el proceso de convertirse en hombre y finalmente desvelar las confrontaciones vividas por los participantes respecto a la masculinidad en el proceso de construcción de la identidad docente. La investigación es cualitativa, con un enfoque exploratorio. Para la construcción de los datos, se adoptan entrevistas semiestructuradas. Los resultados apuntan a una tensión constante entre el ideal inalcanzable de la masculinidad hegemónica y la ruptura creativa con este parámetro.
\end{abstract}

Palabras clave

Masculinidad. Enseñanza. Subjetividad. Educación juvenil y de adultos.

\section{Introdução}

A demanda por equidade, embora tenha surgido através das mulheres, só é realizável com a participação dos homens, haja vista caber a eles a gestão de muitos espaços institucionais, posições de poder e bens econômicos. Esse envolvimento se dá de forma ambígua, pois simultaneamente os homens participam da dominação e devem, eles mesmos, adequar-se ao parâmetro normativo da masculinidade hegemônica (CONNELL, 2016).

Nessa direção, caberia aos sujeitos adequar-se à maneira mais correta de ser homem. Criam-se, assim, estratificações no interior desse grupo e legitima-se a dominação das mulheres (CONNELL, 2016). Essas dinâmicas atravessam todo o corpo social, sendo regularmente constatadas no interior de instituições como a escola (JUNQUEIRA, 2013; SILVA; DIAS; RIOS, 2020), marcando os processos de subjetivação dos homens - e, em nosso caso, dos homens professores - desde a mais tenra idade.

Isso posto, vale ressaltar que entendemos por subjetividade "[...] a maneira pela qual o sujeito faz a experiência de si mesmo" (FOUCAULT, 2006, p. 236). Não há, contudo, uma subjetividade pronta, mas processos de subjetivação. Nós os estudamos a fim de identificar "[...] o que deve ser o sujeito, a que condições ele está submetido, qual o seu status, que posição deve ocupar" (FOUCAULT, 2006, p. 235). Quando essas 
singularidades são professores, os modos de subjetivação são visualizados através de "[...] acontecimentos que transformam relações, saberes, exercícios, livros" (CORAZZA, 2009, p. 103).

Assim, o presente artigo reflete sobre o problema das tensões experimentadas por três homens docentes da Educação de Jovens e Adultos (EJA) em face do dispositivo da masculinidade hegemônica. Como objetivo, propomo-nos compreender os modos como esse dispositivo atuou nos processos de subjetivação dos participantes da pesquisa. Dito isso, este artigo se organiza do seguinte modo: inicialmente, apresentamos a metodologia adotada; logo após, exploramos, no desenvolvimento, três dimensões centrais do problema em análise (a negação da sensibilidade, as ambiguidades do corpo e a transição de aluno a professor); e, por fim, apontamos algumas implicações desses resultados para a formação e para a atuação do docente homem na EJA.

\section{Metodologia}

Adotamos, no presente estudo, a abordagem qualitativa de enfoque exploratório, interessada na compreensão em profundidade de uma experiência vivida pelos participantes da pesquisa (SANDÍN ESTEBAN, 2010). A abordagem qualitativa atravessou as escolhas epistemológicas do início ao fim do texto, guiando-nos nas opções teóricas, na organização dos instrumentos para a construção dos dados e na escolha da técnica de análise do material textual obtido.

Organizamos a investigação nas seguintes etapas: na fase exploratória, realizamos a revisão bibliográfica e a análise documental do Projeto Pedagógico do Curso (PPC) de Especialização em EJA. Finalizada essa fase, procedemos à composição da amostra de participantes. Os parâmetros para essa composição foram: ser discente da pós-graduação; identificar-se como homem; e, por fim, exercer a docência na EJA. Uma vez definidos esses critérios, realizamos uma busca ativa na turma do curso, por meio de convite. Três alunos se disponibilizaram para participar: Antônio, Samuel e Roberto (nomes fictícios).

Antônio tem 50 anos, é negro, estudou somente em escolas públicas. Além de professor licenciado em Pedagogia, é policial militar. Casado, mora com esposa e filhos. Já Samuel tem 46 anos, é pardo, estudou somente em estabelecimentos públicos. Em 
instituição privada, cursou a licenciatura em Geografia, disciplina na qual exerce a docência na EJA. É casado, mora com esposa e filhos. Roberto, por sua vez, tem 26 anos, é pardo, frequentou somente escolas públicas, licenciou-se em Educação Física em uma instituição privada. Como os outros dois participantes, é casado e mora com esposa e filhos. Todos os entrevistados assinaram o Termo de Consentimento Livre e Esclarecido.

Adotamos um roteiro de entrevista semiestruturada como instrumento de construção dos dados. Produzido a partir de categorias próprias do referencial teórico utilizado na pesquisa, o roteiro se constituiu de duas partes. Na primeira, constava um breve questionário socioeconômico. $\mathrm{Na}$ segunda - focada diretamente no problema da investigação -, havia três eixos: família, vida escolar e prática docente.

As entrevistas ocorreram no mês de outubro de 2019. Para a análise delas, no interior dos procedimentos habituais da pesquisa qualitativa em Educação, recorremos à Análise Textual Discursiva (ATD). Inspirada em Foucault (1988), a ATD entende o discurso como prática de articulação entre poder e saber, na qual está superada toda oposição simplista entre dominado e dominante. $O$ discurso (mas também o silêncio) pode ser, concomitantemente, veículo e efeito do poder, bem como uma barreira para ele.

Para mobilizar teoria e campo empírico, focamo-nos nos atravessamentos entre os conteúdos das falas dos participantes e as condições históricas que lhes permitem dizer - ou não dizer - o que enunciam. Fizemos isso cientes de que as práticas discursivas dos participantes nos viabilizam os modos como eles dão sentido ao devir-docente (CORAZZA, 2009) e ao devir-homem a partir de seus discursos (BENTO, 2012).

A ATD se organiza em três etapas: unitarização, categorização e produção do texto (MORAES; GALIAZZI, 2006). No presente estudo, esse processo resultou nas seguintes categorias: 1) a negação da sensibilidade como iniciação à "pedagogia da masculinidade" (MISKOLCl, 2010); 2) o corpo e as ambiguidades do sensível; e 3) alunos e professores: os enfrentamentos na escolha pela docência.

\section{As pedagogias das masculinidades nos processos de subjetivação de homens professores da EJA}

À maneira foucaultiana, compreendemos os processos de subjetivação em sua vinculação indissociável aos dispositivos, caracterizados por serem uma "[...] rede de 
mecanismos entrecruzados" (FOUCAULT, 1988, p. 47). Ao definir a noção de dispositivo em Foucault, Agamben (2005, p. 14) explica que se trata de "[...] qualquer coisa que tenha de algum modo a capacidade de capturar, orientar, determinar, interceptar, modelar, controlar e assegurar os gestos, as condutas, as opiniões e os discursos dos seres viventes". Ademais, "[...] todo dispositivo implica [...] um processo de subjetivação".

Certamente, a definição de Connell (2016, p. 259) da masculinidade hegemônica como uma "[...] configuração de práticas organizadas em relação à estrutura das relações de gênero" dialoga fortemente com a perspectiva foucaultiana. Isso porque não é possível pensar os gêneros fora da dinâmica histórica e de suas regularidades discursivas - como mostrou Albuquerque Júnior (2013) em sua arqueologia do macho nordestino -, tampouco das conexões entre saber, poder e prazer - conforme revelou Bento (2012) em sua pesquisa sobre as mudanças nas subjetivações masculinas. Assim, os modos de pensar, dizer e fazer se encontram habilitados por práticas que, à maneira foucaultiana, são práticas discursivas (MEZZAROBA; CARRIQUIRIBORDE, 2020, p. 10).

Desde o nascimento, o sujeito é objeto de muitos investimentos discursivos sobre o gênero que lhe seria apropriado, fato traduzido em "[...] papéis, traços de caráter, direitos, obrigações e um número finito de possibilidades" (CAMPOMAR et al., 2020, p. 21). Sob essa óptica, tratou-se de perceber pontualmente os encontros desses homens com a masculinidade hegemônica como dispositivo de subjetivação inscrito na cultura. A categorização, disposta nos títulos das seções seguintes, sintetiza os encontros entre os sujeitos e o assujeitamento, processo que encontra no corpo o lugar de sua materialização (BUTLER, 2019).

\subsection{A negação da sensibilidade como iniciação à pedagogia da masculinidade}

A primeira questão da entrevista visava a conhecer a trajetória de vida dos sujeitos. Antônio, desde cedo, não tem a figura do pai e é criado entre quatro irmãos homens. Samuel e Roberto, ambos criados por seus avós, compartilham com Antônio um contexto espaço-temporal peculiar: o campo rural. Os responsáveis pelas crianças, sobretudo os homens, dedicavam muito tempo ao trabalho com a roça e pouco à atenção aos filhos e netos. Em seus relatos, notamos não só a ausência das figuras

Educ. Form., Fortaleza, v. 6, n. 2, e4378, maio/ago. 2021

DOI: https://doi.org/10.25053/redufor.v6i2.4378

https://revistas.uece.br/index.php/redufor/index 
masculinas no lar, mas a falta de espaço para a sensibilidade. No espaço doméstico, inclusive, foi revelada uma experiência de violência.

Faz-se mister relembrar a importância da família como instância inicial dos processos de socialização, principalmente no que diz respeito ao aprendizado dos papéis de gênero e aos usos do corpo. O similar pertencimento de classe dos três participantes também tem implicações na socialização primária. Nas classes populares, há outros usos e mesmo uma outra consciência do corpo e dos fenômenos e práticas associados a ele: a higiene e os cuidados com a beleza, a sexualidade e o prazer, o uso dos espaços domésticos e a privacidade (BOLTANSKI, 1971).

Roberto, por exemplo, relata ter dormido em um dos quartos com um tio. Em um dado momento, esse parente o expulsou do cômodo, fato que levou a criança, a partir de então, a dormir em um colchão no chão na sala. Durante a infância, Roberto conviveu com seus avós, uma tia e esse tio, do qual foi vítima de agressões verbais e físicas.

As memórias infantis desse participante estão repletas de desenhos animados, dentre os quais Cavaleiros do Zodíaco e Dragon Ball Z. Trata-se de produções orientais com temática de combate físico, não raro de violência, que fizeram um enorme sucesso à época. Roberto indica-nos uma significativa influência desses personagens na sua vida, notadamente na construção de traços da virilidade, como a coragem e a força física. Sua experiência dialoga, assim, com a masculinidade como sinônimo de força e dominação (HAROCHE, 2013), bem como nos remete à necessidade de "[...] exagerar a performance da masculinidade" (CONNELL, 2016, p. 140) para se diferenciar sobretudo das mulheres e dos homossexuais, como veremos abaixo.

Roberto menciona igualmente a ausência de oportunidades para demonstrar suas fraquezas: "Fui muito espancado pelo meu tio... Não tinha uma figura paterna para me defender e aquilo me dava uma tristeza muito grande, né?". Os impactos desses episódios na sua subjetivação são constantes ao longo da entrevista. Ademais, ao ser xingado por seu tio, a homossexualidade era evocada como insulto: "Ele [...] me chamava de gay, né, de veado". Segundo ele, heterossexual, isso o fez enxergar o homossexual "[...] como algo ruim". Sobre isso, ainda complementa: "Eu era xingado constantemente e aquilo me dava uma raiva, uma sensação de insegurança, de impotência e de falta de proteção" (grifo nosso). 
Dos três participantes, Roberto apresenta mais detalhes sobre esse que é um dos mais violentos componentes dessa "pedagogia da masculinidade" (MISKOLCl, 2010): referimo-nos ao aprendizado ao qual os meninos são submetidos com vistas a exorcizar qualquer traço capaz de distanciá-los da masculinidade, sob o risco de serem associados à feminilidade e, quase que por consequência, à homossexualidade (JUNQUEIRA, 2013). Experiência similar é apresentada por Antônio: "Se a gente fosse se agarrar com um menino, a família sempre dizia: 'Isso é coisa de fresco [...]'. Mas a gente sempre se reprimia nesse sentido (de brincadeira de chegar e abraçar o outro)".

Ser sensível implica reconhecimento das próprias fragilidades, uma abertura aos próprios afetos e aos de outrem. Ambientes hostis, como os da educação dos nossos participantes, são marcados pelo medo da impotência (HAROCHE, 2013) e combatem o tempo inteiro o desenvolvimento da sensibilidade, retroalimentando o dispositivo da masculinidade hegemônica. O preço disso é a mutilação das subjetividades, com consequências diversas na história dos envolvidos, inclusive em suas dinâmicas afetivas.

É relevante notar como esses dados coincidem com os relatos das nossas entrevistas, mostrando os atravessamentos dos discursos e das subjetividades. Enquanto Antônio diz: "Quando eu estava triste, eu procurava minha família", Samuel e Roberto afirmam, respectivamente, ter práticas semelhantes àquela época: "Sempre, quando eu estou [estava] triste [...] ou com algum problema, eu sempre procuro [procurava] uma área [...] que esteja só eu" e "Eu chorava escondido [...]. Realmente, quando eu era mais novo, tinha muito a questão mesmo (não chorar)". Negar a sensibilidade era fundamental para se iniciar nos violentos rituais da masculinidade hegemônica.

\subsection{0 corpo e as ambiguidades do sensível}

$\mathrm{Na}$ tentativa de obter alguns elementos a respeito das percepções dos participantes acerca do próprio corpo e das desigualdades de gênero a ele associadas, perguntamos a Antônio se ele não teria alguma memória que o remetesse às distinções entre homem e mulher na infância e/ou na adolescência. Ele responde negativamente. Porém, quando questionamos se ele lembrava de preconceitos raciais, ele aponta outros elementos: "Existia sempre uma discriminação entre os colegas (de quem era moreno,

Educ. Form., Fortaleza, v. 6, n. 2, e4378, maio/ago. 2021

DOI: https://doi.org/10.25053/redufor.v6i2.4378

https://revistas.uece.br/index.php/redufor/index 
de quem era branco)". E acrescenta: "[...] principalmente os homens tinham isso: "Não encosta perto de fulano porque o cabelo vai te furar, [...] vai te sujar".

Braga (2015), ao analisar a constituição discursiva de uma estética dos corpos negros no Brasil, salienta os modos de reativação e apropriação desses discursos. A fala de outrem, recuperada por Antônio, faz parte do arquivo brasileiro de enunciados racistas. "Moreno", na verdade, é uma estratégia linguística de embranquecimento. O distanciamento necessário "para não se furar ou se sujar" aponta para a produção social do estigma, pois o indivíduo é reduzido a "[...] uma pessoa estragada e diminuída" (GOFFMAN, 2013, p. 6) ou até mesmo patogênica.

Impossível medir os efeitos dessa violência na subjetividade de Antônio. Assim, apesar de ter em quem se amparar nos momentos de tristeza, quando perguntado sobre como descobriu o próprio corpo e as práticas ditas "de menino" na infância, as respostas, em sua maioria, foram bastante lacunares: "Nada, porque eu nunca mudei, sempre fui essa pessoa que eu sou". No entanto, a cena acima descrita é tão marcante em sua história que esse "nada" por ele evocado, ao tentar apagar episódios doloridos relativos ao próprio corpo - afinal, ele mesmo é negro -, aproxima-se bastante da negação como estratégia de defesa psíquica.

As mesmas questões foram feitas a Samuel, que diz: "Comecei a me masturbar logo cedo. [...] Era uma loucura". Além da referência à masturbação, ritual de autodescoberta corporal comum entre os meninos, Samuel também traz à tona uma espécie de ritual coletivo de iniciação à virilidade, a saber, a frequência aos prostíbulos: "Eu dormia em cabaré, tinha prazer em dormir em cabaré, mas não era porque eu estava ali que tinha que transar pra ser mais macho".

As práticas sexuais, para Connell (2016), são uma das ocasiões de produção da masculinidade e do aprendizado da heterossexualidade. Com as prostitutas, os jovens exercitam não só performances sexuais estritamente vinculadas à genitalidade, mas uma modulação da afetividade. Existem mulheres às quais se pode recorrer apenas para 0 prazer; em contrapartida, há outras com as quais o exercício do afeto demandará um outro saber-fazer, uma vez que a elas será dirigido o amor: as esposas. As ambiguidades do desejo masculino, assim, imbricam-se fortemente às posições a serem ocupadas ou não pelas mulheres. Nessa ambiência, é curioso notar como, após dizer que "Não tinha que transar pra ser mais macho", Samuel acrescenta: "Eu sou o cabra 
mais medroso do mundo". O macho e o medo, diametralmente opostos, revelam a ambiguidade do sujeito.

Quanto a Roberto, é válido relatar uma cena das suas memórias escolares ao ser questionado sobre a interação com docentes homens e mulheres: "Com homem, era mais resistente, [...] porque os homens tinham cara de durão demais" (grifo nosso). Essa memória evoca características da masculinidade hegemônica - o fato de "ser durão" -, inclusive na escola. Sobre as sociabilidades nesse espaço, Roberto acrescenta: "Acho que eu demonstrava muita masculinidade defendendo meu grupo de amigos. Meus amigos também eram assim, e os pais dos meus amigos também [...]. Os pais [deles] falavam: 'Isso é coisa de baitola'; 'Tem que pegar a menina mesmo". Uma das características da socialização dos garotos, a formação dos "bandos" ou grupos (BAUBÉROT, 2013), não raro conta com a presença de homens mais velhos, cuja função é frequentemente vigiar a virilidade.

Em outro episódio, sua masculinidade foi posta à prova por uma moça: "Só sei que a menina estava me chamando de veado [...]. Eu não sei se ela me queria". O que se segue apresenta mais outro ângulo do problema. Ao ser chamado de "veado", diz Roberto: "Eu fiquei com muita raiva, porque eu relembrei as memórias que eu vivi quando era mais novo [...] e eu agredi a menina". Novamente, observamos o retorno do imperativo do "não negar fogo", presente igualmente na narrativa de Samuel. Curiosamente, no entanto, aquela que deveria ser o objeto de seu afeto torna-se objeto de sua violência. Consoante ressalta Bourdieu (2009, p. 64), "[...] o privilégio masculino é também uma cilada [...] que impõe a todo homem o dever de afirmar, em toda e qualquer circunstância, a sua virilidade", a qual é, "[...] acima de tudo, uma carga".

Para Connell (2016), um outro espaço de feitura do homem é o esporte, sendo ele quase tão importante quanto as práticas sexuais. A performance esportiva envolve "combate ritualizado", constituindo-se como um "[...] lugar de camaradagem masculina, uma fonte de identidade" (CONNEL, 2016, p. 143). Já adulto, o jiu-jítsu funcionou para Roberto como um escape para a sua agressividade: "Na hora dos combates, você derrama muita energia [...] e se torna mais próximo das pessoas". Além disso, e não menos importante no caso desse entrevistado, a conexão com o professor de jiu-jítsu foi decisiva em sua opção pela docência. 


\subsection{De alunos a professores: os enfrentamentos na escolha pela docência}

$\mathrm{Na}$ educação formal, acontece, mais ou menos veladamente, a fabricação das diferenças pela escolarização dos corpos: maneiras de se comportar em diferentes situações, forma de andar, de falar, de vestir e de pensar. Há, na família e na escola, uma vigilância constante visando a assegurar a masculinidade dos meninos (LOURO, 2000). Através da articulação entre episódios familiares e escolares dos nossos entrevistados, diagnosticamos fatores relevantes que, ao menos em partes, teceram a aproximação deles com a docência.

Retornando ao episódio racista mencionado anteriormente, lançamos ainda outro questionamento a Antônio, tentando identificar suas posturas diante das possíveis situações de tristeza. Ele afirma: "Na escola nunca aconteceu isso". E apresenta as razões: "Eu sempre fui aquele aluno que me dedicava aos estudos e sempre fala". Por fim, ainda acrescenta: "Eu nunca tive esse tipo de coisa na escola (de tristeza). Nunca tive".

É curiosa a recorrência quase sucessiva ao advérbio de frequência sempre e ao advérbio de negação nunca. As estruturas linguísticas e discursivas aqui fazem uma interseção importante. Quando se é um sujeito subalternizado, a estratégia de sempre ser "o melhor aluno possível" exige um enorme dispêndio de energia para tentar "compensar" o fato de ser quem se é, com vistas a "[...] uma inclusão consentida em um ambiente hostil" (JUNQUEIRA, 2013, p. 489)1.

O sempre estudar e falar sustenta esse nunca que parece estar prestes a acontecer a todo momento, de formas dissimuladas ou aparentes. $\mathrm{Na}$ verdade, regularmente esse nunca efetivamente acontece: "[...] as relações do cotidiano no interior das instituições vão reproduzir as práticas sociais corriqueiras, dentre as quais o racismo, na forma de violência explícita ou de microagressões" (ALMEIDA, 2019, p. 32). Antônio esforça-se, na verdade, por eximir a escola de qualquer responsabilidade: "Isso não foi a escola, e sim os alunos que iam no carro junto com a gente". Ele parece ignorar, todavia, que o currículo não se exerce somente na sala de aula, mas também fora dela.

Ainda sobre as relações de Antônio com a docência, é importante dizer que ele já atuava como professor nos cursos ofertados pela Polícia Militar, contexto no qual seu

${ }^{1}$ A afirmação de Junqueira (2013) refere-se especificamente a discentes LGBT+, porém acreditamos ser ela igualmente aplicável à multidão de sujeitos abjetos, fora da norma, que povoam o espaço escolar.

Educ. Form., Fortaleza, v. 6, n. 2, e4378, maio/ago. 2021

DOI: https://doi.org/10.25053/redufor.v6i2.4378

https://revistas.uece.br/index.php/redufor/index 
gosto pelo exercício do ensinar já se manifestava: "Quando 'saí' sargento, comecei a dar aula para os outros soldados. Sempre dava aulas, sempre fiz isso". Ademais, duas mulheres marcaram decisivamente o seu encaminhamento para a profissionalização docente: a sua esposa, também ela professora, e uma docente da rede municipal. Esta última profissional notou a dedicação de Antônio por ocasião de um curso de inglês ofertado pela Secretaria de Educação desse município. Sobre o impacto dessa experiência, diz o entrevistado: "Aquilo ali me veio para dar aula no mundo civil. Foi quando eu fiz esse curso [que] fui chamado para dar aula pela prefeitura".

Nas palavras de Antônio, o seu exercício como professor começa no desenvolvimento das atribuições da sua primeira profissão, a de policial militar. Apesar de ser uma sala de aula "diferente", não se pode esquecer que escola e forças militares são instituições disciplinares. Como tais, lançam mão de técnicas capazes de definir "[...] um certo modo de investimento político e detalhado do corpo" (FOUCAULT, 2010, p. 134). Assim, elas normalizam os sujeitos por meio de uma poderosa "[...] maquinaria de controle [...]" (FOUCAULT, 2010, p. 167) que "[...] compara, diferencia, hierarquiza, homogeniza, exclui" (FOUCAULT, 2010, p. 176).

Ademais, esses investimentos anátomo-políticos sobre o corpo, tanto no quartel quanto na escola, são nutridos pelo dispositivo da masculinidade hegemônica. A escola brasileira é historicamente estruturada sobre referências centradas no "[...] adulto, masculino, branco, heterossexual, burguês e 'saudável'” (JUNQUEIRA, 2013, p. 482), e, no cotidiano escolar, encontra-se "[...] um currículo em ação a serviço do enquadramento, da desumanização e da marginalização" (JUNQUEIRA, 2013, p. 490) dos sujeitos situados fora dessas referências.

Já no quartel, completa-se a formação viril iniciada na família ou "nos bandos" de adolescentes aos quais aludimos precedentemente, nos quais o garoto está em contato com seus pares. O serviço militar aparece como o ápice da fabricação da masculinidade, pois nele o rapaz "[...] termina de adquirir a força física, o domínio das armas, a coragem e o sentido da disciplina, tornando-se, enfim, um "homem feito"' (BAUBÉROT, 2013, p. 205).

O "isso" mencionado por Antônio ("Sempre dava aulas, sempre fiz isso") ele sempre fez. Como não nos reportarmos aos excertos precedentes, nos quais o entrevistado reforça o seu constante esforço de ser sempre um excelente aluno ou profissional? Na escola ou na polícia, seu corpo é detalhadamente educado para a 
produção de um sujeito bem-comportado. Sua vida é marcada pela hierarquização simbólica e material operada pelo racismo em articulação às táticas de normalização mobilizadas pelas instituições disciplinares, em dinâmicas educativas formais e não formais.

$\mathrm{Na}$ esteira desses processos educativos não formais, adentramos na narrativa de Samuel. Desde cedo, a interação dele com o aprender e o ensinar parece se revelar no trabalho campesino com o avô: "Ele levava a gente [ao campo]. la e chamava... Ensinava e a gente ia porque tinha muito interesse em aprender alguma coisa". 0 aprendizado também se deu por vias calcadas nas tradições indígenas: "Como ele era caboclo, levava muita mordida de cobra, mas não chegou a óbito porque tinha um ritual que a gente fazia [...]. A gente tem uma sabedoria que foi passada dos avós dele".

A história de Samuel é matizada por saberes tradicionais nos quais se exige, por um lado, certa performance da masculinidade: uso da força, resistência física e exposição constante ao risco de envenenamento por animais peçonhentos. Por outro lado, esses mesmos saberes Ihe permitiram o aprendizado de uma "técnica" ensinada pela avó: dialogar consigo mesmo, numa espécie de "conversa espiritual". Considerando ser por meio do corpo que as técnicas são aprendidas (MAUSS, 2003), através dos saberes indígenas corporificados, Samuel exercita uma masculinidade distinta da dos outros participantes, uma vez que a dimensão espiritual se torna mais nítida. Em contrapartida, sempre que pôde, negou-se ao trabalho braçal na roça, por não se identificar com ele.

Acrescenta ainda uma dificuldade específica com a escolarização: o fato de ser disléxico. Esse transtorno o leva a ter dificuldades de memorização, de reconhecimento e de leitura de algumas palavras, além de provocar a inversão de letras e números. Para Moojen, Barbosa e Gonçalves (2016, p. 53), a dislexia se caracteriza "[...] por um inesperado e substancial baixo desempenho da capacidade de ler e escrever, apesar da adequada instrução formal recebida, da normalidade do nível intelectual e da ausência de déficits sensoriais". Dado o impacto dessa realidade em sua vida escolar, Samuel diz que a educação não era "o forte" dele, mas, no fim das contas, tornou-se professor. Sobre isso, afirma: "Eu não consigo até hoje entender como eu estou na educação, [...] mediante as minhas dificuldades, mas eu costumo compreender como uma questão espiritual'. 
Duas questões nos chamaram a atenção nesses relatos: Samuel diz não desejar nem a agricultura nem a educação. Ademais, diz ter "fugido do campo", mas mora e exerce a docência no campo. Seu desejo, associado às diversas circunstâncias de sua vida, conduziu-o justamente ao que ele dizia não querer e que hoje tem tanta importância em sua vida: ser professor justamente em uma escola campesina. Seus alunos, aliás, são sujeitos cujas dificuldades de aprendizagem se assemelham às suas.

O transtorno de aprendizagem, impresso em seu corpo, exerceu forte influência sobre o modo de ele ser professor, tornando-lhe mais sensível à diversidade dos discentes. Para ele, "Pelo menos se um professor ouvisse; bastava ele ouvir, nós teríamos outro processo de educação". A escuta do outro aparece mais de uma vez na entrevista com Samuel, que termina por associar esse exercício de alteridade às mulheres. Ao relatar as suas relações com professores na graduação, ele afirma se aproximar mais das mulheres, indicando as razões: "Eu acho que elas conseguem me ouvir, entendeu?'. Embora identifiquemos uma visão estereotipada sobre a sensibilidade para a escuta dos outros, também encontramos em Samuel o rompimento desse estereótipo que ele mesmo reproduz.

Foi na Faculdade de Educação Física que o outro participante, Roberto, encontra alguém cuja influência será crucial para a sua escolha pela docência: o professor de jiu-jítsu. Roberto fala dele como um sujeito icônico: "Eu tive uma relação forte de sentimento com meu professor de jiu-jítsu nas artes marciais; foi a primeira vez onde [sic] fui ouvido, foi a primeira vez que alguém me enxergou como importante". E acrescenta: "Eu tive uma inspiração para ser professor de Educação Física devido àquele professor".

Roberto dizia anteriormente não demonstrar sentimentos e não ter se comovido sequer na morte de sua bisavó. Vemos nesse relato, entretanto, uma grande transformação operada pelo encontro com um professor inspirador. Ser ouvido e enxergado foi determinante para Roberto. A partir dessa escuta atenta, mas também do escape para a agressividade proporcionado pelo esporte, ele passou a acreditar que, ao manifestar sentimentos, "Você se torna mais próximo das pessoas".

Diferentemente do que ocorre em outros estudos sobre estereótipos de gênero e formação docente, especificamente na Educação Física (CAMPOMAR et al., 2020), com Roberto se opera uma ruptura com a masculinidade hegemônica. Tal fato se materializou 
por uma prática de escuta, de maneira similar à vivida por Samuel. A relação entre mestre e discípulo, nas artes marciais, revelou-se crucial para uma nova configuração dos afetos e do modo de exercer a docência no caso de Roberto. Certamente, conforme defende Silva (2020), a própria mobilização do corpo e da disciplina no interior dessa prática corporal contribuiu para uma transformação do participante.

\section{Considerações finais}

Nas narrativas de Antônio, Samuel e Roberto, professores da EJA, identificamos que o dispositivo da masculinidade hegemônica se organiza como uma pedagogia às avessas. Nas tensões vividas com a negação da sensibilidade, com o pertencimento étnico-racial e com as práticas afetivo-sexuais e esportivas, os três entrevistados encontram-se ante as ambiguidades do sensível, cujo veículo é o corpo. É nele que se operam os afetos e vínculos, mas também as exclusões potencializadas por estigmas e pelo dispositivo da masculinidade hegemônica. Esse dispositivo violenta física e simbolicamente não somente os homossexuais e as mulheres, mas também os próprios homens heterossexuais, pois se trata de um ideal inatingível (CONNELL, 2016).

Todavia, também é na potência do corpo que se materializam as rupturas com os mecanismos de controle ensejados pelo dispositivo. Referimo-nos: (I) às técnicas aprendidas por Samuel com os saberes indígenas e ao seu modo particular de experimentar os prazeres; (II) ao encontro de Roberto com um professor afetuoso atento ao seu sofrimento; (III) e ao incentivo dado por duas mulheres a Antônio para o exercício da docência. Em todas essas experiências, há algo conectado às funções desempenhadas pelo feminino na cultura, mas sobretudo na (des)ordem dos afetos: 0 feminino aponta para algo que nos falta. Essa falta assinala os processos de formação inicial e continuada desses docentes.

Os resultados exprimem a importância da discussão de gênero na formação dos professores. Inseridos numa outra pedagogia, homens docentes poderão contribuir significativamente para a igualdade de gênero e para a compreensão da masculinidade como uma construção identitária que pode ser desmantelada para dar lugar a uma maneira saudável de ser homem, de ser educador na EJA e de ser sujeito de afetos.

Educ. Form., Fortaleza, v. 6, n. 2, e4378, maio/ago. 2021 


\section{Referências}

AGAMBEN, G. O que é um dispositivo?. Outra Travessia, Florianópolis, v. 5, p. 9-16, 2005.

ALMEIDA, S. L. Racismo estrutural. São Paulo: Sueli Carneiro: Pólen, 2019.

ALBUQUERQUE JÚNIOR, D. M. Nordestino: invenção do "falo". Uma história do gênero masculino (1920 - 1940). São Paulo: Intermédios, 2013.

ANTÔNIO. Entrevista. Canguaretama, 14 out. 2019.

BAUBÉROT, A. Não se nasce viril, torna-se viril. In: COURTINE, J.-J. (org.). História da virilidade 3: a virilidade em crise? Séculos XX-XXI. Petrópolis: Vozes, 2013. p. 190-220.

BENTO, B. Homem não tece a dor: queixas e perplexidades masculinas. Natal: UFRN, 2012.

BOLTANSKI, L. Les usages sociaux du corps. Annales: Economies, sociétés, civilisations, Paris, n. 1, p. 205-233, 1971.

BOURDIEU, P. A dominação masculina. Rio de Janeiro: Bertrand Brasil, 2009.

BRAGA, A. História da beleza negra no Brasil: histórias, discursos e práticas. São Carlos: UFSCar, 2015.

BUTLER, J. Problemas de gênero: feminismo e subversão da identidade. 17. ed. Rio de Janeiro: Civilização Brasileira, 2019.

CAMPOMAR, G. C. et al. "Você não... nessa posição, sim ou sim, um homem": representações em torno do gênero e intervenção docente na formação. Educação e Formação, Fortaleza, v. 5, n. 14, p. 17-35, 2020.

CONNEL, R. Gênero em termos reais. São Paulo: nVersos, 2016.

CORAZZA, S. O docente da diferença. Periferia, Rio de Janeiro, v. 1, n. 1, p. 91-110, 2009.

FOUCAULT, M. Ética, sexualidade, política. Rio de Janeiro: Forense Universitária, 2006.

FOUCAULT, M. História da sexualidade 1: a vontade de saber. Rio de Janeiro: Graal, 1988.

FOUCAULT, M. Vigiar e punir: nascimento da prisão. Petrópolis: Vozes, 2010. 
GOFFMAN, E. Estigma: notas sobre a manipulação da identidade deteriorada. Rio de Janeiro: LTC, 2013.

HAROCHE, C. Antropologias da virilidade: o medo da impotência. In: COURTINE, J.-J. (org.). História da virilidade 3: a virilidade em crise? Séculos XX-XXI. Petrópolis: Vozes, 2013. p. 15-34.

IFRN. Curso de Pós-Graduação Lato Sensu em Educação de Jovens e Adultos no Contexto da Diversidade, na modalidade presencial. Natal: IFRN, 2015.

JUNQUEIRA, R. D. Pedagogia do armário: a normatividade em ação. Revista Retratos da Escola, Brasília, DF, v. 7, n. 13, p. 481-498, 2013.

LOURO, G. L. Pedagogias da sexualidade. In: LOURO, G. L. O corpo educado: pedagogias da sexualidade. Belo Horizonte: Autêntica, 2000. p. 7-34.

MAUSS, M. Sociologia e Antropologia. São Paulo: Cosac \& Naify, 2003.

MEZZAROBA, C.; CARRIQUIRIBORDE, N. Teoria e prática: questões imprescindíveis à prática educativa. Educação \& Formação, Fortaleza, v. 5, n. 3, p. e2807, 2020.

MISKOLCI, R. (org.). Marcas da diferença no ensino escolar. São Carlos: UFSCar, 2010.

MOOJEN, S. M. P.; BASSOA, A.; GONÇALVES, H. A. Características da dislexia de desenvolvimento e sua manifestação na idade adulta. Revista Psicopedagogia, São Paulo, v. 33, n. 100, p. 50-59, 2016.

MORAES, R.; GALIAZZI, M. C. Análise Textual Discursiva: processo reconstrutivo de múltiplas faces. Ciência \& Educação, Bauru, v. 12, n. 1, p. 117-128, 2006.

ROBERTO. Entrevista. 23 out. 2019.

SAMUEL. Entrevista. 18 out. 2019.

SANDÍN ESTEBAN, M. P. Pesquisa qualitativa em educação: fundamentos e tradições. Porto Alegre: AMGH, 2010.

SILVA, L. A. N. A experiência do corpo como fenômeno educativo no Taekwondo. São Paulo: LiberArs, 2020.

SILVA, I.; DIAS, A.; RIOS, P. Os estudos de Gênero na Revista Tempos e Espaços em Educação: uma revisão sistematizada. Educação \& Formação, Fortaleza, v. 5, n. 2, p. 150-175, 2020. 
Avelino Aldo de Lima Neto, Instituto Federal de Educação, Ciência e Tecnologia do Rio Grande do Norte, Programas de Pós-Graduação em Educação Profissional

i-Dhttps://orcid.org/0000-0003-4810-8742

Doutor em Educação pela Université Paul Valéry - Montpellier III e pela Universidade Federal do Rio Grande do Norte. Professor do Instituto Federal de Educação, Ciência e Tecnologia do Rio Grande do Norte (IFRN) e dos Programas de Pós-Graduação em Educação Profissional (PPGEP) da IFRN) e em Educação (PPGED) da Universidade Federal do Rio Grande do Norte (UFRN). Pesquisador do Observatório da Diversidade da IFRN, vinculado ao Conselho Nacional de Desenvolvimento Científico e Tecnológico (CNPq).

Contribuição de autoria: Escrita do referencial teórico e metodológico, análise dos dados e revisão final.

Lattes: http://lattes.cnpq.br/3231870235953025

E-mail:ave.neto@hotmail.com

Rita de Cássia Angelo da Silva, Instituto Federal de Educação, Ciência e Tecnologia do Rio Grande do Norte

ii@ https://orcid.org/0000-0003-4247-4602

Especialista em Educação de Jovens e Adultos pelo Instituto Federal de Educação, Ciência e Tecnologia do Rio Grande do Norte (IFRN).

Contribuição de autoria: Construção dos dados e contribuição no referencial teórico-metodológico.

Lattes: http://lattes.cnpq.br/3991163444439301

E-mail: ritinhaangelo@gmail.com

Robério Nunes Maia, Universidade Federal do Rio Grande do Norte

iii.Dhttps://orcid.org/0000-0002-3468-6122

Mestrando no Programa de Pós-Graduação em Educação da Universidade Federal do Rio Grande do Norte (UFRN).

Contribuição de autoria: Desenvolvimento do referencial teórico a partir da análise dos dados.

Lattes: https://orcid.org/0000-0003-3405-4894

E-mail: roberiohc@hotmail.com

Editora responsável: Lia Machado Fiuza Fialho

Pareceristas ad hoc: Leliana Sousa e Karina Dias

\section{Como citar este artigo (ABNT):}

LIMA NETO, Avelino Aldo de; SILVA, Rita de Cássia Angelo da; MAIA, Robério Nunes. Pedagogias da masculinidade: reflexões acerca de processos de subjetivação de homens professores da EJA. Educ. Form., Fortaleza, v. 6, n. 2, e4378, 2021. Disponível em: https://revistas.uece.br/index.php/redufor/article/view/4378 


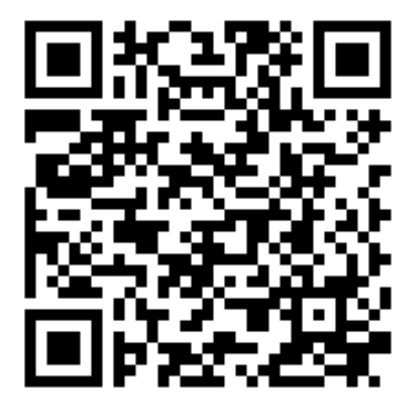

Recebido em 12 de novembro de 2020.

Aceito em 20 de janeiro de 2021.

Publicado em 18 de março de 2021. 